Revista Eletrônica de Educação do Curso de Pedagogia do Campus Avançado de Jataí da Universidade Federal de Goiás [Vol I - n.1 ] [jan/jul] [ 2005 ]

ISSN: $1807-9342$

\title{
TRIGONOMETRIA UTILIZANDO O SOFTWARE CABRI GÉOMÈTRE
}

MACIEL, Viviane Barros - Licenciada em Matemática/CAJ/UFG vivianemat@hotmail.com SILVA, Adriana Batista da - Licenciada em Matemática/CAJ/UFG. CIVARDI, Jaqueline Araújo - Doutora em Educação Matemática/UB - Docente CCM/CAJ/UFG jaqtek@hotmail.com

BARBOSA, Katiuse Cabral - Licenciada em Matemática/CAJ/UFG

REIS, Maria Elidia Teixeira Reis - Mestranda em Educação/CAJ/UFG

MONTEIRO, Agner Candida B - Licenciada em Matemática/ CAJ/UFG

SILVA, Regina E. de Jesus - Licenciada em Matemática/CAJ/UFG

SILVEIRA, Graciele P - Licenciada em Matemática/CAJ/UFG

RESUMO: O presente artigo tem como objetivo apresentar o relato de uma experiência pedagógica em que tratou-se de ensinar a trigonometria utilizando o software Cabri Géomètre. Tal experiência pautou-se em uma proposta que tinha como objetivos levar o aluno a: i) relacionar o conteúdo de semelhança de triângulos com o das razões trigonométricas, obtidas e aplicadas a situações problemas de tipo reais e recreativos e ii) explicar oralmente e por escrito essas mesmas razões utilizando o software Cabri Géomètre. Tal proposta está inserida, no contexto, de uma pesquisa desenvolvida por integrantes do Núcleo de Investigação em Educação Matemática - NIEMAT, do Campus Avançado da Universidade Federal de Goiás em Jataí que buscam compreender as argumentações geométricas, desenvolvidas por alunos do ensino fundamental, em duas situações de aulas distintas: uma em que professor responsável pela disciplina ministra as aulas de geometria e outra em que são os estagiários, licenciandos em matemática, assumem a regência de tais aulas.

Palavras-chave: Geometria - Trigonometria - Problema - Informática - Cabri

\begin{abstract}
The article has objective to present a report of a pedagogyc experiene in wich will be taught trigonometry using the cabri géomètre software. This experience has suport in a proposition wich objectives are leting the student to: i) refer the triangle's likeness contents with the trigonometrics quocient contents, resulted and aplicated to problems situations of real kinds and recreative and ii) explain orally and writting these same quocient using the cabri géomètre sftware. This proposition is inserted in the context, of a research developed by components of the investigation Nucleus in Mathematics Education - (NIEMAT - Núcleo de Investigação em Educação Matemática), from Campus Avançado de Jataí/Universidade Federal de Goiás, in Jataí, that seeks understanding the geometric arguments, developed by primary school students, in two diferente classes situations: one in wich the responsable maths teacher presents the geometry lessons, and another in wich the probationers are the ones, licensed in maths, assume the regency of these classes.
\end{abstract}

Key-words: Geometry - Trigonometry - Problem - Informatic -Cabri

Introdução

No presente artigo temos como objetivo apresentar o relato de uma experiência pedagógica e alguns resultados relevantes obtidos a partir do ensino da trigonometria utilizando o software cabri-géomètre e o método de resolução de problemas para um grupo de alunos do ensino fundamental. Na proposta tínhamos especificamente como objetivos que o aluno explicasse oralmente e expressasse por escrito as razões trigonométricas na sua forma genérica. Para isto procuramos que o aluno relacionasse o conteúdo de semelhança de triângulos com o das razões trigonométricas e que esta relação fosse obtida da experimentação 
e manipulação de triângulos retângulos usando o cabri e da observação e do estudo dos triângulos retângulos em situações contextualizadas.

Precisamente foram planejadas e desenvolvidas estratégias de ensino para o conteúdo de razões trigonométricas, que foram levadas a cabo durante o ano de 2003, em uma sala de aula da $8^{\mathrm{a}}$ série do ensino fundamental da rede pública numa realidade em que $82 \%$ dos alunos não possuía computador particular ou não sabia manejá-lo e a escola não dispunha de um laboratório para realizar tais atividades.

O desenvolvimento de uma proposta de ensino da trigonometria para alunos da $8^{\mathrm{a}}$ série surgiu de uma discussão efetuada pelos integrantes do Núcleo de Investigação em Educação Matemática - NIEMAT do Campus Avançado de Jataí/Universidade Federal de Goiás (CAJ/UFG), que desde dezembro de 2002 vem trabalhando em uma pesquisa que procura investigar as ações e procedimentos de estagiários do curso de Matemática e de professores em atuação e as argumentações dos alunos em resposta às práticas desses atores que atuam em um mesmo ambiente de ensino e aprendizagem. Dessas discussões analisamos a viabilidade e o potencial didático e conceitual de desenvolver uma proposta de ensino da trigonometria já no ensino fundamental que foi aplicada por duas estagiárias do curso de licenciatura em matemática e que pertenciam ao NIEMAT. Chegamos então à conclusão de que o tratamento de certos conceitos da trigonometria no ensino fundamental, relacionando-os com conceitos geométricos, seria campo fértil tanto para o desenvolvimento de certas habilidades cognitivas dos alunos quanto para os objetivos de nossa investigação.

\section{Das etapas iniciais até a aplicação da proposta pedagógica}

Foram quatro as etapas até o desenvolvimento da proposta pedagógica. A primeira etapa se caracterizou pela observação das aulas da professora em atuação onde ocorreu o estágio supervisionado. A segunda pelo desenvolvimento de uma pesquisa bibliográfica sobre o tema. A terceira pela elaboração da proposta pedagógica tendo como base a pesquisa bibliográfica e dados obtidos durante a etapa de observação. Finalmente a quarta pela aplicação e avaliação das ações desenvolvidas.

A etapa de observação ocorreu durante o primeiro trimestre de 2003, quando foi percebido que nas aulas de geometria, a professora utilizava basicamente como recursos didáticos a lousa, o giz, o transferidor, a régua, o esquadro de madeira, além do livro didático, de onde provinham as tarefas que eram resolvidas em sala pelos alunos. Além disso, um outro ponto importante que foi observado, diz respeito ao ensino-aprendizagem do conteúdo de 
semelhança de triângulos, a maioria dos alunos sentiu dificuldades de aprendizagem do conceito o qual foi trabalhado sob o enfoque mais demonstrativo.

Percebemos ainda que, em vários momentos, os alunos giravam o caderno para melhor visualizarem os elementos do triângulo retângulo (catetos e hipotenusa) e que a professora encontrava certa dificuldade em explicar o conteúdo utilizando apenas a lousa e o esquadro como recursos didáticos.

Concomitante à etapa da observação ocorreu a etapa da pesquisa bibliográfica quando buscamos, nos Parâmetros Curriculares Nacionais - PCN's (Brasil, 1998), orientações que nos pudessem auxiliar na elaboração de objetivos e estratégias de ensino das razões trigonométricas. Além dos PCN's, as obras de Barbosa (2001), Borba e Godoy (2001), Paiva (1997), Rabelo (2002) e Varizo (1993) foram importantes no que diz respeito à justificativa da proposta e à eleição dos recursos e estratégias que poríamos em prática durante o período de desenvolvimento da proposta pedagógica.

Quanto à etapa da elaboração da proposta pedagógica, esta ocorreu posteriormente ao período da observação e do desenvolvimento da pesquisa bibliográfica e nela descrevemos e sintetizamos as idéias relevantes (que serão apresentadas logo abaixo) que nortearam toda a ação pedagógica levada a cabo no terceiro bimestre do ano letivo de 2003, além de propormos o planejamento específico de cada atividade didática por unidade de ensino.

Quanto à última etapa que caracterizamos pelo desenvolvimento da proposta pedagógica, explicitaremos, neste artigo, alguns dos resultados e as conclusões que chegamos a partir da avaliação que efetuamos durante e após a ação pedagógica e que serão apresentados posteriormente à descrição da ênfase teórica que demos ao nosso trabalho.

\section{Da observação à ênfase teórica e desta à elaboração da proposta}

A dificuldade do aluno, que é um dos sujeitos de nossa pesquisa, em compreender o conceito de semelhança de triângulos através do uso do método de demonstração e a necessidade que este sentia de girar o caderno para visualizar formas e elementos do triângulo retângulo, em parte, nos levou a buscar no computador e no software cabri meios para auxiliá-lo no processo de aprendizagem das razões trigonométricas. Borba e Godoy (2001) afirmam que as novas mídias, como os computadores, enfatizam um aspecto muito importante que é experimentação. Esta por sua vez se torna algo fundamental, à medida que inverte a ordem de exposição oral da teoria com exemplos e exercícios bastante usuais no ensino tradicional, e possibilita uma nova ordem que parte da investigação até chegar à dos 
conceitos. Além do mais, os recursos tecnológicos trazem significativas contribuições para o processo de ensino-aprendizagem de matemática, à medida que possibilita o desenvolvimento de um crescente interesse dos alunos pela realização de projetos e atividades de investigação.

Esses autores chamam a atenção para o fato de que o uso do computador nas aulas de matemática podem servir como um grande aliado no desenvolvimento cognitivo. Para nós, a idéia de Barbosa (2001), sobre o papel que o computador cumpre na aprendizagem complementa a de Borba e Godoy (2001) à medida que essa autora defende que esse recurso tecnológico apresenta um grande potencial educativo, pois auxilia o professor a identificar aspectos relevantes sobre desempenho do aluno dentro daquilo que Vygotsky conceituou como zona de desenvolvimento proximal.

A partir dessas duas idéias entendemos que o professor de posse de informações sobre as funções cognitivas num estado embrionário, pode servir-se do computador para auxiliá-lo no processo de aprendizagem do aluno. Entendemos ainda que o computador pode servir como poderso instrumento mediador utilizado no processo de aquisição dos conceitos matemáticos, uma vez que o dinamismo característico desse tipo de recurso permite criar situações em que o aluno é incentivado a criar desequilíbrio em sua estrutura cognitiva fazendo-o avançar no sentido de uma nova e mais elaborada estruturação conceitual, passando de conceitos espontâneos a conceitos científicos.

Um outro aspecto não menos importante que nos levou a escolha do computador como recurso didático para nossas aulas foi o fato de que essa mídia se adapta a diferentes ritmos de aprendizagem (PCN's), característica esta detectada ainda no grupo observado durante a primeira etapa do trabalho.

Aliado ao computador, utilizamos o software cabri géomètre que segundo Paiva (1997) é um instrumento que permite ao aluno a possibilidade de visualizar, experimentar, conjecturar e coordenar de forma dinâmica os movimentos dos objetos matemáticos e daí abstrair as propriedades observáveis, o que não seria possível em um ambiente tradicional de sala de aula.

Em nossa proposta o uso do computador e do cabri esteve aliado à utilização do método de resolução de problemas, que ao nosso ver são perfeitamente compatíveis à visão de aprendizagem e ao papel do professor apresentado anteriormente. A resolução de problemas foi pensada como um ponto de partida que pudesse disparar um processo de construção do conhecimento matemático (Rabelo, 2002). E os tipos de problemas que utilizamos inicialmente para contribuir na formulação dos conceitos de razões trigonométricas foram de caráter recreativos e reais. Quanto ao computador e ao cabr,i estes nos serviram como 
instrumentos mediadores no processo de elaboração e aquisição dos conceitos trigonométricos, constituindo-se recurso educativo para identificar habilidades cognitivas dos alunos e como instrumentos utilizados na criação de desequilíbrios cognitivos que permitissem ao aluno elaborar conceitos mais formais a partir daqueles mais espontâneos, surgidos durante o processo de observação e experimentação vivenciado pelo aluno.

No que diz respeito ao papel das estagiárias, gostaríamos de dizer que estas procuraram atuar como facilitadoras nesse processo.

É importante observar finalmente que a opção metodológica adotada na proposta pedagógica se adequou aos objetivos estabelecidos pelos componentes do NIEMAT e se configuraram em levar o aluno a: a) relacionar o conteúdo de semelhança de triângulos ao das razões trigonométricas, de forma que este obtivesse e aplicasse as razões estudadas em situações contextualizadas e b)explicar oralmente e por escrito essas mesmas razões utilizando o software Cabri Géomètre.

\section{Da aplicação da proposta aos resultados}

A proposta foi aplicada em uma escola conveniada, numa sala de aula da $8^{\mathrm{a}}$ série do Ensino Fundamental, do turno matutino, que possuía um total de 35 alunos, com faixa etária variando entre 12 a 16 anos. A proposta foi desenvolvida em 20 aulas, de 50 minutos cada, no período de Agosto a Outubro, em ambientes diversificados como: sala de aula, sala de monitoria, laboratório de informática, disponibilizado pelo Núcleo Tecnológico Educacional de Jataí - NTE e subvencionado pelo governo municipal, e academia de ginástica e musculação, localizada próxima à escola. A ação pedagógica, como dissemos, foi desenvolvida por duas estagiárias (que no ano de 2003 cursavam o curso de licenciatura em matemática no CAJ/UFG) e que pertencem ao NIEMAT e ocorreu paralelamente às aulas de outros conteúdos matemáticos ministrados pela professora da turma.

A seguir detalharemos alguns dos momentos da aplicação da proposta e três resultados significativos que obtivemos com o desenvolvimento da proposta:

Momento 1: Revisão do conceito de semelhança de triângulos 
Esse momento propôs a detectar quais eram os conhecimentos prévios que o aluno possuía sobre o conceito de semelhança de triângulos. No que diz respeito à semelhança de triângulos, verificamos que muitos estudantes apresentavam dificuldades em caracterizar as propriedades dessa classe de triângulos e definir conceitos a eles relacionados. Vários alunos relacionavam esta dificuldade ao esquecimento do conteúdo estudado no $2^{\circ}$ bimestre. A tentativa de sanar tal problema passou pela revisão deste conteúdo, tanto em sala de aula, quanto nas aulas de monitoria no turno vespertino.

\section{Momento 2: Descoberta das razões trigonométricas}

Antes de o aluno ter contato com o computador e com o cabri, lhe foram-lhe passados duas tabelas, devendo uma delas ser preenchida com medidas dos ângulos e lados dos triângulos retângulos encontrados nos equipamentos de musculação de uma academia de ginástica (ver Figura 1) e a outra preenchida com as razões encontradas entre os lados dos triângulos. É importante dizer que o aluno durante o recolhimento desses dados obteve informações sobre os aspectos positivos da educação física para a saúde da pessoa e os cuidados que uma pessoa deve tomar durante o desenvolvimento de certas atividades físicas.

De posse dos dados coletados, os pesquisadores deveriam levar para as aulas no laboratório as tabelas com os resultados obtidos durante a visita à academia e a partir daí construir no cabri triângulos semelhantes aos encontrados nos equipamentos.

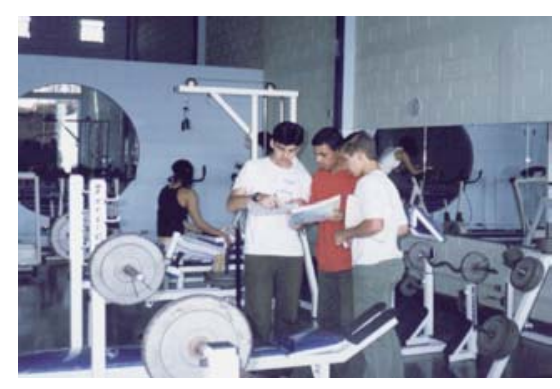

Figura 1: Alunos recolhendo dados das medidas dos lados dos triângulos na academia

Momento 3: Manuseio do cabri-géometrè II 
O momento 3 se propôs a ensinar ao aluno a manusear o cabri Géomètre II. Para alcançar o objetivo anterior, das oito aulas realizadas no NTE foram necessárias seis para que os alunos conhecessem os principais comandos e recursos do software. Salientamos que o conhecimento desses comandos foi ocorrendo paulatinamente e à medida que às tarefas iam sendo propostas, isto é, para cada sessão de aula em que se propunham tarefas específicas e diferentes exigia-se do aluno, diferenciadas habilidades instrumentais e cognitivas. Isto fazia com que em cada aula o aluno tivesse que aprender um novo comando para realizar a tarefa proposta. Quanto aos resultados, apresentaremos a seguir quatro deles os quais consideramos significativos, dentro da perspectiva de nosso trabalho.

Resultado 1: Os alunos conseguem estabelecer relações entre as razões trigonométricas e o conceito de semelhança nos triângulos retângulos

As razões trigonométricas foram uma descoberta efetuada pelos alunos de acordo com o que foi estabelecido no planejamento inicial e foram necessárias oito sessões de aulas para que os alunos percebessem que a razão entre o cateto oposto a um ângulo e a hipotenusa, ou a razão entre cateto oposto e adjacente a esse ângulo, ou ainda entre cateto adjacente e hipotenusa desse mesmo ângulo são constantes entre si porque se tratavam de triângulos também semelhantes entre si. A terminologia de seno, cosseno e tangente foi apresentada formalmente, depois que as relações foram estabalecidas pelos alunos.

Resultado 2: Os alunos conseguem com habilidade aplicar os conceitos de razões trigonométricas em diferentes situações problemas.

Ao final das aulas no NTE, foi observado ainda que os alunos conseguiram com habilidade resolver em sala de aula tarefas de trigonometria e aplicar os conceitos construídos em diferentes situações problemas.

Através de uma avaliação no final do curso foi constatado também que os alunos conseguiam apresentar argumentações escritas bastante elaboradas, como no exemplo que apresentamos a seguir, mostrando assim o alcance positivo que teve o desenvolvimento de tal proposta. 
De acordo com Faria (1998), o aluno junto com o professor, deve ter a oportunidade e a liberdade de falar, ouvir, escrever e ler dentro do processo de ensino e aprendizagem. No entanto, muitas vezes o aluno não se comunica satisfatoriamente com um adulto porque ainda não tem as mesmas generalizações que aquele. Assim, segundo este autor, a ação pedagógica na aula de matemática deve estar voltada para a formação de significados cada vez mais generalizados e estar centrada na construção de significados através do diálogo que por sua vez dá margem a um ensino voltado para o desenvolvimento de um processo argumentativo que leva à construção de conceitos mais significativos.

Nas primeiras aulas, durante o período em que foi aplicada a proposta pedagógica, constatamos que os alunos quase não dialogavam, aparentemente, tinham receio em falar. Assim que estes começaram a ser instigados e se conseguiu estabelecer um diálogo entre alunos e estagiárias surgiram os primeiros insights relativos aos temas propostos para aquelas aulas. Quando estes ocorriam, apesar de muitos alunos terem dificuldade em generalizar os conceitos, comunicavam-se sem maiores medos. Um exemplo disto foi quando os alunos verificaram que a razão entre o cateto oposto e a hipotenusa do ângulo de $60^{\circ}$ equivalia aproximadamente ao número 0,87 e que este valor era constante em outros triângulos semelhantes àqueles que estavam representados na tela do computador.

Tal descoberta provocou euforia em alguns dos alunos que diante dela insistentemente chamavam a atenção das estagiárias para verificar a validez da propriedade descoberta. A ação das estagiárias ante tal situação foi pedir aos alunos que argumentassem oralmente o que estavam observando e instigar os alunos para que verificassem o que ocorria com as razões quando o ângulo era de $30^{\circ}$.

À medida que vivenciavam tais experiências, os alunos conjecturavam, desenvolviam relações, criavam argumentos e retroalimentavam seus raciocínios, como já ocorreu em outras situações em que se usou no cabri (Barbosa, 2001)

\section{Resultado 3: Aprendizagem mais significativa de aluno com dificuldade em matemática}

No início do ano letivo, ainda no período de observações, percebemos que havia certos alunos com dificuldades em Matemática e que dispunham de pouco tempo para dedicação aos estudos. Durante a aplicação da proposta, pudemos constatar que houve crescimento na aprendizagem por parte de alguns deles e exemplificaremos aqui um caso que mostra o avanço de um aluno (o qual denominaremos Edmilson) durante a ação pedagógica. 
Edmilson era um aluno que ao inicio do ano letivo sentia grandes dificuldades em apresentar soluções coerentes aos problemas propostos. Este fato ainda foi constatado nas aulas iniciais ocorridas no NTE, quando Edmilson apresentou muitas dificuldades, tanto na redação de suas respostas às tarefas propostas durante as aulas quanto no manuseio dos recursos computacionais.

Notamos que paulatinamente algumas das dificuldades (principalmente aquelas ligadas à explicitação oral e à redação mais lógica de seus argumentos) sentidas pelo aluno foram sendo superadas na última aula ocorrida no NTE. Edmilson foi um dos primeiros a constatar que as razões trigonométricas são constantes em triângulos retângulos semelhantes.

$\mathrm{Na}$ avaliação que ocorreu ao término do desenvolvimento da ação pedagógica, Edmilson conseguiu o máximo aproveitamento numa prova de nove questões em que $80 \%$ das questões eram de nivel intermédio a intermédio avançado, isto é, para que as questões fossem resolvidas necessitava-se do emprego de mais de dois conceitos matemáticos. Uma tarefa em que se pediu para que se encontrasse o sen $45^{\circ}$, o cos $45^{\circ}$ e a tg $45^{\circ}$ sendo dado, a Figura 2, é um exemplo que nos mostra o avanço e o bom domínio dos conceitos estudados por Edmilson, pois ele conseguiu...

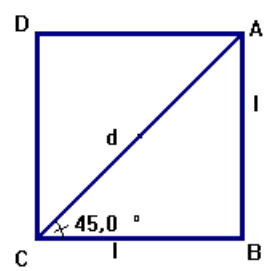

Figura 2: Quadrado ABCD

Edmilson apresenta a seguinte solução ao problema:

$$
\begin{aligned}
& \operatorname{sen} 45^{\circ}=\frac{\text { cat.op }}{\text { hip. }} \frac{l}{l \sqrt{2}}=\frac{1}{\sqrt{2}} \\
& \cos 45^{\circ}=\frac{\text { cat.adj }}{\text { hip. }} \frac{l}{l \sqrt{2}}=\frac{1}{\sqrt{2}} \\
& \operatorname{tg} 45^{\circ}=\frac{\text { cat.op }}{\text { cat.adj }}=\frac{l}{l}=1
\end{aligned}
$$

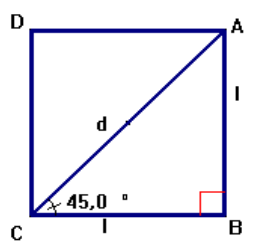

$\mathrm{d}^{2}=1^{2}+\mathrm{l}^{2}$

$\mathrm{d}^{2}=2 \mathrm{l}^{2}$

$\mathrm{d}^{2}= \pm 1 \sqrt{2}$ 
Apresentamos a seguir algumas conjecturas sobre os desencadeadores da mudança na estrutura da resposta dada pelo aluno. Falamos em conjecturas, uma vez que uma análise sistemática sobre o tema deve ser feita posteriormente no decorrer de nossa pesquisa.

\section{- Algumas considerações sobre o resultado 3}

Conjecturamos que os diferentes processos cognitivos desenvolvidos pelo aluno durante as atividades no laboratório de informática e as relações aí estabelecidas, assim como a visualização no computador, o raciocínio no papel e o método de resolução de problemas foram ao nosso ver facilitadores, motivadores e disparadores de uma aprendizagem mais significativa e da busca de soluções ao problema matemático.

De acordo com relatos feitos pelo próprio aluno, o método e os recursos didáticos utilizados pelas estagiárias assim como o próprio papel assumido por elas abriram uma porta para que ele pudesse aprender e tomar gosto pelo aprendizado, como podemos constatar no depoimento abaixo, dado pelo próprio aluno.

Trecho de uma redação do aluno Edmilson ao final da aplicação da proposta: Vocês duas nos fez, nos confiar em nos mesmos, pois nós nunca achávamos que iríamos ser capaz de aprender a fazer aquele trabalho no computador. Eu Edmilson, não conhecia nada daquilo, mas vocês abriram uma porta para eu passar. Não posso falar que não gostei de nada, porque aprendi muito com vocês. Queria ter uma outra chance para ser seu aluno de novo.

O depoimento anterior nos apresenta uma outra faceta quando se usa o computador nas aulas de matemática, como evidencia a discussão a seguir:

Resultado 4: Maior motivação dos alunos nas aulas ocorridas no ambiente iformatizado

Observou-se no decorrer da ação pedagógica que houve uma maior motivação por parte dos alunos em estudarem a geometria em um ambiente diferente ao da sala de aula como nos mostra o relato das estagiárias.

Trecho de uma reflexão efetuada pelas estagiárias ao final da aplicação da proposta: Desde a primeira aula que foram ministradas no NTE, os alunos mostraram-se entusiasmados ao acessarem o software cabri géomètre, ao descobrirem como funcionava alguns comandos do software, assim como visualizar as primeiras figuras construídas por eles. No rosto de cada um deles percebia-se estados de annimos positivos como 
surpresa, alegria, satisfação entre outras, principalmente quando eles conseguiam movimentar as figuras geométricas, como foi o caso de uma aluna que exclamou: "Olha podemos movimentar o triângulo, ele fica girando!".

As estagiárias continuam a sua reflexão mostrando que alguns alunos não associam as aulas tidas no laboratório como sendo de matemática.

Trecho de uma reflexão efetuada pelas estagiárias ao final da aplicação da proposta: A satisfação sentida pelos alunos nas aulas de matemática levou alguns deles a pedirem para que não se fosse embora, pois na escola teriam aula de matemática. Diante dessa colocação nós respondemos ao aluno que as aulas no NTE também eram de matemática. $\mathrm{O}$ aluno nos disse então que se todas as aulas de matemática fossem assim, queria estudar só matemática. Isso nos mostra a admiração e a perplexidade deles diante das mídias informáticas. Esta admiração também pôde ser comprovada nas redações matemáticas que realizavam no final das aulas ocorridas no laboratório de informática. Nestas redações pedíamos para que descrevessem os pontos positivos e negativos das aulas que estavam sendo realizadas no NTE.

Não é o nosso objetivo discutir o que levou alguns dos alunos a não considerarem a aula de geometria, tida no laboratório de informática, como estando associada à disciplina de matemática. Apresentaremos a seguir mais do que reflexão de caráter mais analítico um ponto de vista sobre o uso do cabri nas aulas de geometria.

\section{- Algumas considerações sobre o resultado 4}

Confirmando as afirmações de Barbosa (2001) que diz que a visualização e a movimentação permitida com o uso do cabri géomètre representa para o aluno um novo panorama, possibilitando a exploração de figuras geométricas em várias posições, acreditamos que a aprendizagem da matemática utilizando outras mídias possibilita o abrir de um mundo antes inexplorado pelo aluno. O cabri quando bem empregado permite a este construir, colorir e movimentar as formas geométricas, o que, segundo Barbosa (2001), tratase de uma das maiores riquezas do software.

Acrescentamos finalmente que o uso de outras mídias diferentes da lousa e do giz associadas ao processo de ensino e aprendizagem que vai desde a experimentação até a teorização leva o aluno a exercitar com maior liberdade seu poder de criação, organização, análise e síntese. 
Este trabalho poderia ser comparado a uma vitrine da pesquisa que os componentes do NTE está desenvolvendo sobre as argumentações geométricas de alunos da $8^{\mathrm{a}}$ série do ensino fundamental quando estes têm aulas tanto com estagiários do curso de licenciatura quanto com seus próprios professores de matemática. Neste artigo não entramos no mérito central do que nos propusemos com nossa pesquisa. Nossa intenção foi mostrar um relato de alguns resultados decorridos de uma experiência pedagógica que está vinculada o nosso trabalho investigativo e apresentar algumas reflexões sobre os mesmos. Queriamos, indiretamente, com esse relato, animar os nossos colegas de profissão, os professores de matemática do ensino fundamental, a buscar estratégias de ensino que mobilizem melhor o raciocínio e criatividade de seus alunos.

Observamos com a experiência relatada nesse trabalho que as conjecturas como as feitas por determinados alunos no NTE, podem ser associadas à ampla experimentação feita por eles dentro e fora da sala de aula. E o professor, desde sua formação inicial, deve preocupar-se em compreender e ser crítico quanto ao uso das tecnologias no ensino.

As inovações educacionais pressupõem mudanças na prática docente. $\mathrm{O}$ computador provoca uma mudança na dinâmica da aula, a qual exige do professor novos conhecimentos e ações. A integração do computador à oralidade e à escrita traz o surgimento de novos estilos de conhecimento e se torna um dispositivo técnico através do qual percebemos o mundo e estruturamos nossas experiências.

A partir dessa experiência, percebeu-se também que o livro didático não é fonte exclusiva de informações para os alunos e ainda que a sala de aula não é o único ambiente de aprendizagem formal da matemática. Atualmente as informações podem ser obtidas através dos mais variados recursos. No entanto, para que haja aprendizagem e geração de novos conhecimentos durante o desenvolvimento de novas práticas pedagógicas é necessário que estas informações sejam organizadas e discutidas, permitindo, desse modo, que mais estudantes tenham acesso a estudar matemática e a formalizar conceitos a partir de situações contextualizadas.

É importante salientar que ao trabalhar em ambientes diferentes, o professor corre o risco de se defrontar com situações inesperadas durante a aula, pois como nas aulas do NTE, o aluno ficou livre para fazer conjecturas e propor soluções. Ao tentar uma nova prática, o professor terá uma surpresa ao verificar que seus alunos terão maior domínio dos conceitos matemáticos, maior flexibilidade em explorar idéias matemáticas deixando de ser meros observadores de matemática. 
Acreditamos que, diante da possibilidade de se alcançar resultados tão positivos, vale a pena passar pela zona de riscos (Borba, 2001). Ainda mais se considerarmos que as propostas contidas no texto poderão tornar as aulas de matemática mais agradáveis, contribuindo para a redução do número de reprovações em matemática e evitando que sejam repetidas as práticas de épocas em que as mídias predominantes eram outras.

Sabemos também que as limitações existem e são variadas, mas o professor não pode deixar abater-se por elas. A luta por mudanças é a melhor resposta que o professor pode dar às situações que em muitas ocasiões desumanizam a ação desse profissional.

\section{Referências Bibliográficas}

BARBOSA, A. C. M. Investigando e justificando problemas geométricos com o Cabri II. Boletim 39 - GEPEM. Set., p. 51-72.2001.

BORBA, M. C. e GODOY, M. P. Informática e Educação Matemática. Rio de Janeiro: Autentica, 2001.

BRASIL, Parâmetros Curriculares Nacionais - PCN's: Matemática 3 e $4^{\circ}$ ciclos, 1998.

FARIA, C. de O. Redação Matemática: A comunicação como mediadora na formação de conceitos matemáticos. Inter-Ação. Revista da Faculdade de Educação - UFG. Goiânia: Editora da UFG, p. 13-31, 1998.

PAIVA, M. A. V. et. ali. Cabri: Descobrindo a geometria no computador. $1^{\text {a }}$ ed. Vitória, ES: LEACIM/CCE, PPGE/UFES, 1997.

VARIZO, Z. C. N. O Ensino da Matemática e a resolução de problemas. Inter - Ação. Revista da Faculdade de Educação - UFG, Goiânia: Editora da UFG, 1993. 
